\title{
Nuevas tendencias de la política exterior en el siglo XXI
}

Intervención del Ministro de Relaciones Exteriores, don Ignacio Walker, en la inauguración del programa de Magister 2005 del Instituto de Estudios Intemacionales de la Universidad de Chile (Santiago, 13 abril de 2005).

1. Nos encontramos ante un mundo cada vez más interconectado y complejo, cuyas características más notorias son la incertidumbre y el cambio permanente. Nunca como ahora el poder político, las relaciones sociales, la cultura y los factores económicos internacionales han sido tan complejos y variables, por lo cual se hace imprescindible adaptar métodos de análisis e instrumentos para la acción que nos permitan comprender mejor la realidad que nos rodea y actuar de manera más eficaz en la globalización.

2. Los esquemas bipolares -Este/Oeste, Norte/Sur, Mundo desarrollado/Mundo subdesarrollado u otros- ya no son suficientes para explicar las dinámicas que dirigen los cambios experimentados en las últimas décadas y que sin duda se profundizarán en el futuro.

3. Potencias emergentes en Asia, una Europa que se está rediseñando, un Medio Oriente que sigue inestable, divisiones transatlánticas, una América Latina que ha sabido ir consolidando su identidad regional y que presenta a veces desequilibrios y vul- 
nerabilidades en sus sociedades, y una sola superpotencia dominante son algunos ejemplos de estos cambios. La magnitud y la velocidad de ellos determinarán en las siguientes décadas la política exterior mundial.

4. Pero también temas como la seguridad humana, en el más amplio de sus sentidos, el terrorismo, el deterioro del medioambiente y la gobernabilidad se encuentran en el centro de los desarrollos recientes y aquellos por venir.

5. En términos generales, el mundo globalizado que nos está tocando vivir tiende a acercar distancias, acortar tiempos y homogenizar procesos. No obstante, algunos de los paradigmas de la globalización han resultado ser perversos, pues acrecientan diferencias muchas veces muy profundas entre los beneficiados y los olvidados por ella.

6. Sin embargo, es indudable que en la toma de las decisiones globales se ha producido un fenómeno de apertura e inclusión sin precedentes en la historia, no solo en lo que se refiere a los actores, sino que también en lo tocante a los temas y factores que inciden en ellos.

Crisis del Estado soberano y surgimiento de nuevos actores en la escena internacional.

7. El actor internacional por excelencia es el Estado, que es, a la vez, sujeto de derecho internacional. Sin embargo, no es el único, ya que junto a él actúan en el concierto mundial otras entidades, como los organismos internacionales, y otras formas y procesos supranacionales relativamente recientes, que superan en muchos ámbitos al Estado-nación. Un ejemplo de estos últimos es la Unión Europea, la que, sin haber reemplazado a sus Estados miembros, actúa en ciertos ámbitos como una entidad internacional distinta de ellos.

8. Tampoco debe soslayarse la creciente presencia que la sociedad civil y determinadas regiones han alcanzado en el concierto internacional, influyendo de manera directa en la toma de decisiones de política exterior de sus respectivos entornos nacionales. 
9. Al mismo tiempo, se seguirán desarrollando tendencias Documentos orientadas a protegerse frente a la pérdida de identidad -cultural, económica, política, etc.- provocada por la globalización, a fin de generar espacios de concertación y sinergia para hacerse valer en el mundo globalizado. Ejemplos son el caso de la ya mencionada Unión Europea, el Grupo de Río, las Cumbres Iberoamericanas, la Unión Africana y APEC.

10. En todo caso, y contrariamente a lo que se ha sostenido con frecuencia, el Estado-Nación no está en vías de desaparición. Por el contrario, ciertos desarrollos locales de autodeterminación e independencia ocurridos en las últimas dos décadas parecieran reforzar su primacía como actor internacional.

11. Pero de lo que no puede haber duda es que el tradicional concepto de soberanía ha cambiado. En un proceso controlado por la propia voluntad estatal, la soberanía ha dejado de ser exclusiva, autónoma y plena. La soberanía de unos, limitada por la de otros, está también sujeta a mayores exigencias de la cooperación internacional, del sistema de paz y seguridad, de un sinnúmero de actividades transnacionales y de la protección de la persona humana. En este proceso ha jugado un rol importante el creciente desarrollo del Derecho Internacional.

12. Los nuevos y variados actores que están ingresando en el escenario internacional a la par de los Estados les están disputando la exclusividad de ser sujetos de derecho internacional, calidad que compartían hasta ahora solo con los organismos internacionales mundiales $y /$ regionales.

13. Hoy participan en el contexto internacional las ONGs, los partidos políticos a través de sus "Internacionales"; organizaciones religiosas y humanitarias; grupos étnicos; las empresas transnacionales, que llegan a mover capitales mayores que el PIB de muchos países; etc. En general, se puede hablar de una presencia cada vez más articulada a través de sus múltiples manifestaciones de una sociedad civil internacional.

14. A ello deben sumarse como actores -querámoslo o no- 
lo que algunos han denominado como amenazas transnacionales: Documentos las bandas o agrupaciones del crimen organizado internacional, del narcotráfico, el terrorismo, el tráfico ilegal de armas, entre otros, son actores internacionales de identidad difusa que interactúan con los demás actores, influyendo en sus decisiones y acciones. Aprovechando los beneficios de la globalización, manipularán flujos financieros e inversiones a través del "lavado de dinero", para influir o incluso manejar gobiernos y procesos económicos.

\section{LA PERSONA COMO ACTOR INTERNACIONAL Y LA SEGURIDAd Humana}

15. Especial mención merece la persona humana en el contexto de los nuevos actores internacionales. El individuo se ha consagrado en décadas pasadas, no solo como sujeto de derecho internacional, sino que también como actor y testigo presencial del. debate internacional. Este fenómeno se ha enriquecido con una perspectiva de creciente vigencia y que no disminuirá en las décadas venideras, si consideramos el solo hecho de los avances que hoy existen en las comunicaciones y la informática, los que facilitan la presencia real y virtual de la persona común y corriente en el debate mundial.

16. La promoción y protección de los derechos humanos, el derecho internacional humanitario, la preocupación por ciertos grupos y personas más vulnerables y, más recientemente, el desarrollo del concepto de seguridad humana han recogido esta realidad.

17. Desde comienzos de los años ' 90 , y a instancias del PNUD, la seguridad humana se reinstaló en la agenda internacional como seguridad del pueblo, no solo del territorio; como seguridad de las personas, no solo de las naciones; seguridad a través del desarrollo, no a través de las armas; seguridad de las personas en todas sus dimensiones y en todos los lugares y entornos.

18. La creciente trascendencia que ha adquirido queda refle- 
jada en la creación de la Red de Seguridad Humana, grupo de países -al cual pertenece Chile-que mantiene, a nivel de Ministros de Relaciones Exteriores, un diálogo sobre cuestiones vinculadas con la seguridad humana, y cuyos esfuerzos están enfocados, entre otros, a temas tales como la universalización de la Convención de Ottawa sobre Minas Antipersonales, el establecimiento de la Corte Penal Internacional, la protección de los niños en conflictos armados, el control de las armas pequeñas y ligeras, la lucha contra el crimen organizado internacional, la educación en derechos humanos, la lucha contra el SIDA y la implementación del derecho humanitario internacional.

19. Lo anterior cobra tanto más importancia si se tiene en cuenta que para los próximos decenios se prevé una expansión de la población mundial, la que se estabilizaría en la segunda mitad del siglo en alrededor de 12 mil millones de habitantes. Si los parámetros estructurales de desarrollo actual se mantienen, el mundo continuará presentando sensibles diferencias en las tasas de desarrollo económico entre el Norte y el Sur, agravando el tema de las migraciones, generando permanentes conflictos y también problemáticas de derechos humanos.

20. Encontrar respuestas adecuadas frente a las grandes migraciones, las que involucran a millares de personas que buscan mejores horizontes, será uno de los grandes dilemas que deberán enfrentar las políticas nacionales de inmigración.

21. Nuestro país no está ajeno a este fenómeno. El creciente flujo de inmigrantes, originarios especialmente de nuestro entorno vecinal, debe ser enfrentado con realismo y políticas prácticas. No es posible ignorar este fenómeno por el contrario, deben buscarse soluciones prácticas y legales que tiendan a incluir este conjunto humano en el proceso de desarrollo integral de nuestro país.

22. Relacionado con lo anterior, pero más complejo aún, es el caso de los refugiados, que presenta complejidades inmensas, y sobre el cual incumbe una gran responsabilidad de conducción y ordenamiento a la organizaciones internacionales, sobre todo, cuando se producen en torno a crisis humanitarias y conflictos armados internos. 
23. Definimos como globalización a la serie de fenómenos de alcance planetario que tienden a acrecentar la interdependencia e interconexión de los flujos de personas, bienes, servicios, información, tecnología y capital, sustentados en la revolución tecnológica, la conformación de un mercado y de una cultura de dimensiones mundiales, el aumento del comercio y de la producción en red.

24. La globalización posee una dinámica extensiva de carácter geográfico, que incluye progresivamente a todas las regiones de la tierra, al mismo tiempo que tiende a incrementar sus efectos internos relativos a cada país, llegando a modificar conductas y valores tradicionales que hasta ese momento guiaban a los individuos que conforman dichas sociedades.

25. La economía globalizada, el avance tecnológico, el acceso casi ilimitado a la información son ejemplos de la creciente interconectividad e interdependencia de los países más allá del nivel estatal-gubernamental. Ello hará que los individuos, las empresas, en general la sociedad civil, hagan valer cada vez con mayor fuerza su voz en el contexto de las políticas exteriores de sus respectivos países.

26. Lo anterior conducirá al fenómeno que se puede denominar "desestadualización de la política exterior". Los vínculos Estado-Estado y gobierno- gobierno dejarán en forma creciente de ser exclusivos y excluyentes, $y$ en el concierto internacional participarán en forma cada vez más directa otros actores transnacionales, cuyos intereses se entrecruzan con aquellos de los primeros.

27. Pero esa "desestadualización" no solo se refiere a los "actores", sino que también a los "temas". No serán solo asuntos relacionados a la relación interestatal los que ocuparán la agenda internacional, sino que problemas o fenómenos que escapen de dicho ámbito.

28. Para mencionar solo algunos ejemplos, señalemos el ca- 
lentamiento global de la atmósfera, los desastre naturales, el narcotráfico, movimientos de solidaridad transfronteriza, la internet, etc.

\section{Algunas RESPUESTAS A LA GLOBALIZACIÓN Y SUS DERIVADOS}

29. La aparente pérdida de validez de principios, creencias y valores tradicionales, que se consideraban universales y permanentes, hace que las alternativas axiológicas de los próximos decenios sean determinantes en la emergencia de creencias y valores alternativos y apropiados.

30. La diversificación e inclusión de nuevos actores y temas internacionales puede generar temores de desorden entre los Estados y dar la impresión de "perder el norte" en la búsqueda de soluciones a los problemas que aquejan a nuestro planeta.

31. Ese fue el desafío que abordó la Cumbre del Milenio, celebrada con ocasión de la Asamblea General de Naciones Unidas del año. En esa oportunidad, se adoptó una resolución, la cual, sobre la base de principios básicos universales de convivencia -la tolerancia, la solidaridad, la igualdad, la libertad, el respeto por la naturaleza, la responsabilidad-, cristalizó un "programa de acción" que pretende enfrentar con éxito lo que todos los países sentían eran los cambios que el nuevo siglo XXI traería consigo.

32. En la "Declaración del Milenio" los países reconocen su responsabilidad en enfrentar con éxito dichos desafíos que surgen de la "mundialización que, si bien ofrece grandes posibilidades, en la actualidad sus beneficios se distribuyen en forma muy desigual al igual que sus costos".

33. Esa responsabilidad debe encauzarse principalmente hacia la gestión del "desarrollo económico y social en el mundo" y hacia la lucha contra las "amenazas que pesan sobre la paz y seguridad internacionales".

34. Es así como la "Declaración del Milenio" fijó una serie de 
objetivos clave a ser visualizados para enfrentar los desafíos de la globalización. La paz, la seguridad y el desarme fueron confirmados como prioridades irrenunciables, junto con la erradicación de la pobreza y la lucha por un mayor desarrollo. Por otro lado, reconoce la importancia del medioambiente y su conservación, fijando pautas para protegerlo, destacando implícitamente las dificultades que emanan de lograr el desarrollo sostenible.

35. También menciona a la democracia como mecanismo idóneo para lograr lo gobernabilidad del mundo globalizado que enfrentamos, destacando el respeto de los derechos humanos como condición previa. También erige a la persona humana, especialmente la más desprotegida y vulnerable, en receptora de asistencia y protección internacional, lo cual reafirma la tendencia a considerar al individuo como actor y sujeto de derecho internacional.

36. Por último, menciona la reforma integral de Naciones Unidas, reconociendo en ella y en el multilateralismo los mecanismos más apropiados para enfrentar conjuntamente los desafíos del siglo XXI. Al respecto, reconoce la importancia de los "nuevos actores", como las ONGs, la sociedad civil y al sector privado, al ofrecerles la "oportunidad de contribuir a las metas y programas de la Organización”.

37. Este "plan de acción" indica que se busca echar las bases para una política exterior más participativa. Si a ello agregamos la reciente propuesta de reforma de Naciones Unidas presentada por el Secretario General, sobre la base de las sugerencias del Panel de Alto Nivel, es la idea de "inclusión" la que pareciera dominar en los futuros desarrollos de la política exterior: mayor número de miembros en el Consejo de Seguridad, mayor participación regional en sus organismos, mayor participación y atribuciones de la Asamblea General, mayores y mejores canales de contacto con otras organizaciones regionales, mayor interacción con la sociedad civil internacional, entre otros.

38. En este escenario, constituye una de las prioridades de la política exterior chilena su definición en el ámbito multilateral, como un proceso político activo y participativo, al mismo tiempo que 
como un medio para proyectar la política exterior haciéndose cargo de los desafíos del siglo XXI. Por eso, Chile se siente interpretado por la "Declaración del Milenio" y ha actuado en consecuencia. La mantención de la paz y seguridad en el mundo, la promoción de los derechos humanos y de los valores democráticos, la cooperación para el desarrollo sostenible, entre otros, son parte integrante de la agenda internacional chilena.

39. Creemos que uno de los desafíos de nuestros países es la gobernabilidad de la globalización. Ella requiere necesariamente mantener, desarrollar y establecer espacios -amplios y abiertosy mecanismos -universales y consensuados- que sean capaces de regularla en sus distintos planos. Al concluir Chile varios acuerdos de libre comercio, ha mostrado tener confianza en el hecho de que es posible dotar a la globalidad y a los intercambios con otras naciones de instrumentos de ordenación y armonización de políticas y acciones. Esto implica mayor atención a los compromisos asumidos, un Ministerio de Relaciones Exteriores con alto nivel profesional, y una forma de trabajo integradora en el plano interno, tanto a nivel gubernamental como de construcción de consensos políticos y sociales aptos para asumir estas tareas.

40. Las organizaciones multilaterales, ya sean mundiales o regionales, constituyen otros espacios idóneos donde convergen las voluntades políticas de los Estados, y ellas han sido y seguirán siendo, el marco más apropiado para la elaboración y codificación de normas de conducta y convivencia internacionales.

41. En este esfuerzo, el derecho internacional es el mecanismo más apropiado. La creciente ampliación de su ámbito de aplicación y su progresiva codificación ha entregado a los Estados independientes un marco que les ayuda a no "perder el norte", como señalábamos más arriba. Así, el "dominio reservado" del Estado, mejor definido de esta manera, ya no es necesariamente antagónico con la búsqueda de los beneficios de un "dominio común", donde conviven los intereses de todos los actores internacionales.

42. El derecho internacional, por ello, necesariamente seguirá 
evolucionando para adaptar sus normas a las exigencias siempre cambiantes de la globalización. En ese sentido, son elementos importantes de la mencionada evolución dos fenómenos que irán afianzándose cada vez más: por un lado la incorporación del derecho internacional por las legislaciones nacionales y su aplicación por los tribunales nacionales, y por el otro la creciente utilización de sistemas internacionales de solución de controversias (jurisdicción obligatoria), como ocurre en el caso de la protección de los derechos del individuo o el comercio internacional.

43. Es una decisión del Gobierno de Chile el mantener la alta tradición en cuanto a una política exterior activa, inspirada en principios de derecho internacional, y continuar contribuyendo a la generación de regímenes y principios que favorezcan su desarrollo e inserción pacífica, en asociación con la región Recordemos la importancia que tienen para nuestro país áreas como el derecho del mar, el régimen antártico, la integración física, y un conjunto de acuerdos bilaterales y regionales que sirven de base a nuestra identidad como país.

\section{CONCLUSIÓN}

44. E1 siglo XXI que recién empezamos a recorrer nos ofrece desafíos de tal magnitud, que cualquier intento de diseñar o entender la política exterior de los Estados de manera estrecha, compartimentada o aislada del entorno que nos rodea, conducirá necesariamente al fracaso.

45. Por el contrario, una actitud abierta y comprensiva, que incorpore la óptica de que las relaciones internacionales se dan en un sistema dinámico, con equilibrios y también disparidades, facilita la generación de una política exterior inclusiva, que recoja y proyecte a Chile como parte activa de la comunidad global.

46. Y para ello, Chile no solo demuestra en distintas instancias, foros y convenciones su amplitud de criterio para entender el escenario que se nos abre, con todas sus complejidades y matices, sino que también ha manifestado su volüntad y disposición de co- 
laborar y aportar con ideas y acciones concretas en beneficio de

Documentos todos los actores interesados, invirtiendo todas nuestras energías para neutralizar los eventuales peligros que nos acechan en beneficio de la integración con la región y el resto del planeta. 